\title{
RISK FACTORS FOR CENTRAL VENOUS CATHETER- RELATED INFECTIONS IN PEDIATRIC INTENSIVE CARE
}

\author{
Ricardo Vilela1 ${ }^{1}$, Andréa D N Jácomo², Antonia Teresinha Tresoldi²
}

Vilela R, Jácomo ADN, Tresoldi AT. Risk factors for central venous catheter-related infections in pediatric intensive care. Clinics. 2007;62(5):537-44.

OBJECTIVES: To identify risk factors for short-term percutaneously inserted central venous catheter-related infections in children and to evaluate the accuracy of a mortality score in predicting the risk of infection.

METHOD: After reviewing the charts of patients who developed catheter-related infection in a university hospital's pediatric intensive care unit, we conducted a case-controlled study with 51 pairs. Variables related to patients and to catheter insertion and use were analyzed. Risk factors were defined by logistic regression analysis. The accuracy of the Pediatric Risk of Mortality score to discriminate the risk for infection was tested using the Receiver Operating Characteristic curve.

RESULTS: Infection was associated with respiratory failure, patient's length of stay, duration of tracheal intubation, insertion of catheter in the intensive care unit and parenteral nutrition. Insertion site (femoral or internal jugular) was unimportant. Multivariate logistic regression analysis identified the following variables. Risk factors included more than one catheter placement $(\mathrm{p}=0.014)$ and duration of catheter use $(\mathrm{p}=0.0013)$, and protective factors included concomitant antibiotic use $(\mathrm{p}=0.0005)$ and an intermittent infusion regimen followed by heparin filling compared to continuous infusion without heparin $(\mathrm{p}=0.0002)$. Pediatric Risk of Mortality did not discriminate the risk of infection.

CONCLUSIONS: Central parenteral nutrition and central venous catheters should be withdrawn as soon as possible. Femoral vein catheterization carries a risk of infection similar to internal jugular catheterization. The Pediatric Risk of Mortality score should not be used to predict the risk of central catheter-related infections.

KEY-WORDS: Cross Infection. Risk Factors. Catheterization. Central Venous. Child. Intensive Care.

\section{INTRODUCTION}

Bloodstream infection (BSI) related to intravenous therapy is an important factor in morbidity, mortality and hospital costs, especially in intensive care. Most hospitalacquired BSIs are associated with the use of a central venous catheter (CVC). Catheter-related bloodstream infection (CRBSI) rates are influenced by patient-related parameters, such as severity of illness, and by catheter-related param-

1. State University of Campinas (UNICAMP) - Clinical Hospital, Pediatric Intensive Care Unit

2. State University of Campinas (UNICAMP) - Clinical Hospital and Medical Science Faculty

Email: ricardovilela@superig.com.br

Received for publication on March 02, 2007

Accepted for publication on May 21, 2007 eters, such as the material comprising the device. Additionally, utilization conditions should be considered, including insertion techniques, catheter care and solutions infused, ${ }^{1}$ along with unique considerations of pediatric patients. ${ }^{2}$

Some studies aimed at prevention and surveillance have estimated the risk for this and other nosocomial infections. Low specificity was obtained when using risk scores like Pediatric Risk of Mortality (PRISM) values. ${ }^{3,4}$

From January 2002 through December 2003, 875 patients were admitted to the Pediatric Intensive Care Unit (PICU) of this university hospital, with 17.8 central lineassociated BSIs per 1000 central line-days in 2002 and 25.8 in 2003.

Such rates motivated this study, which aims to identify risk factors for the development of short-term percutane- 
ously inserted central venous catheter-related infection (CRI) in children and to evaluate the accuracy of a pediatric mortality score in predicting the risk of infection.

\section{MATERIALS AND METHODS}

\section{Sample selection}

In the two years of study, the PICU used catheters from the same manufacturer (Arrow International Inc, USA). There were no changes in the standards of care, including aseptic insertion technique, catheter site dressing, access to ports or filling the lumen with a heparin solution, when receiving intermittent infusion.

Patients reported as having CRI, according to the criteria of Pearson and HICPAC, ${ }^{5}$ were identified in the files of the hospital infection control committee, and their charts were reviewed. A retrospective 1:1 case-control study was conducted, where controls were defined by catheter placement close in time to the cases. A previous observation was that infection was always diagnosed 4 or more days after catheter insertion, in 10 randomly selected cases. For that reason, the minimum length of stay accepted for controls was 4 days.

\section{Variables}

Variables included in the case-control study were related to both patients and technical aspects of catheter insertion and utilization. Patients were evaluated for age, gender, Zscore of weight for age and gender, length of stay in the PICU, underlying conditions, reason for admission, duration of tracheal intubation, previous antibiotic therapy, PRISM on admission, and exit (discharge or death). Catheter variables included scene, operator, site and order of insertion, as well as the length of time it remained in place. Other variables were concomitant antibiotic therapy, use of CVC for administration of blood products, infusion of parenteral nutrition through CVC and regimen of infusion, which could be continuous or intermittent, alternating with heparin. Catheters without continuous infusion were filled with a 50U/ $\mathrm{mL}$ heparin solution, after administration of intermittent medications (e.g., antibiotics, sedatives). Catheters with continuous infusion (e.g., hydration, parenteral nutrition, vasoactive drugs) were not filled or flushed with heparin.

\section{Statistical analysis}

$\mathrm{SAS}^{\circledR} 8.2$ for Windows was used for statistical analysis, with a level of significance of $5 \%$.

With the aim to select variables associated with infec- tion that could act as risk factors, preliminary statistical analysis compared cases and controls by Chi-square analysis, Fisher exact test for proportions and Mann-Whitney test for continuous and ordinal variables.

Variables associated with infection in the preliminary tests were then analyzed by univariate logistic regression in order to identify risk factors for infection. The most important set of risk factors was then selected by stepwise multivariate logistic regression analysis. The Receiver Operating Characteristic (ROC) curve was used to test discriminatory power of the PRISM score.

\section{Ethical aspects}

The medical science faculty research ethics committee approved this study.

\section{RESULTS}

In 27 cases, the same microorganism was isolated from cultures of both the peripheral blood and the catheter tip. Thirteen other cases had BSIs with positive blood culture but negative or contaminated catheter tip culture. These 13 patients experienced a decrease in fever after removal of the catheter and initiation of empirical antibiotic therapy for CRBSI. Six additional cases had clinical sepsis with negative blood culture and experienced a decrease in of fever after removal of the catheter and initiation of antibiotic therapy. Five patients had exit-site infection.

Table 1 shows general characteristics of the study sample.

\section{Microrganisms}

Blood cultures were positive in 40 cases, and catheter segment cultures were positive or considered contaminated by laboratory standards in 45 cases. The most frequent microorganisms in blood samples were Staphylococcus aureus (34.1\%), Staphylococcus epidermidis (11.4\%), Klebsiella pneumoniae (9.0\%) and Enterobacter sp (9.0\%). Candida tropicalis was present in two blood cultures (4.5\%).

\section{Preliminary statistical analysis}

Using Chi-square analysis, infection was associated with age 1 to 2 years $(p=0.032)$, PICU stays longer than 15 days $(\mathrm{p}=0.005)$, more than one CVC placement $(\mathrm{p}=0.009)$, no antibiotic therapy $(\mathrm{p}<0,0001)$, parenteral nutrition $(\mathrm{p}=0.016)$ and continuous infusion regimen without heparin filling $(\mathrm{p}=0.0001)$. Fisher exact test identified an association between infection and admission for respiratory 
Table 1- Demographic and clinical characteristics.

\begin{tabular}{|c|c|c|c|}
\hline Characteristics & Cases & Controls & $\mathrm{p}$ \\
\hline Number & 51 & 51 & \\
\hline \multicolumn{4}{|l|}{ PRISM } \\
\hline$\leq 10$ & 32 & 33 & \\
\hline de 10 a 30 & 16 & 13 & \\
\hline$>30$ & 2 & 4 & \\
\hline Age in months (median) & 13,5 & 7,8 & \\
\hline \multicolumn{4}{|l|}{ Age } \\
\hline$<1$ year & 23 & 29 & \\
\hline 1 to 2 years & 17 & 6 & 0,032 \\
\hline$>2$ years & 11 & 16 & \\
\hline \multicolumn{4}{|l|}{ Gender } \\
\hline Female & 20 & 27 & \\
\hline Male & 31 & 24 & \\
\hline \multicolumn{4}{|l|}{ Weight } \\
\hline Low (Z-score < -2) & 27 & 22 & \\
\hline Appropriate (Z-score $\geq-2$ ) & 24 & 29 & \\
\hline \multicolumn{4}{|l|}{ Underlying conditions } \\
\hline Chronic lung disease & 12 & 5 & \\
\hline Cardiac disease & 10 & 4 & \\
\hline Chronic renal failure & 3 & 8 & \\
\hline Steroid therapy & 6 & 7 & \\
\hline \multicolumn{4}{|l|}{ Reason for admission } \\
\hline Elective operation & 4 & 13 & \\
\hline Sepsis & 4 & 9 & \\
\hline Respiratory failure & 36 & 21 & 0,013 \\
\hline Cardiac failure & 4 & 12 & \\
\hline Other & 3 & 6 & \\
\hline \multicolumn{4}{|l|}{ Length of stay in the PICU } \\
\hline$\leq 7$ & 9 & 19 & \\
\hline de 8 a 14 & 20 & 24 & \\
\hline$\geq 15$ & 22 & 8 & 0,005 \\
\hline \multicolumn{4}{|l|}{ Tracheal intubation } \\
\hline No & 1 & 3 & \\
\hline$<24$ hours & 2 & 6 & \\
\hline 1 to 7 days & 7 & 19 & \\
\hline$>7$ days & 41 & 23 & 0,001 \\
\hline Death & 9 & 3 & \\
\hline \multicolumn{4}{|l|}{ Catheter insertion scene } \\
\hline PICU & 48 & 38 & 0,009 \\
\hline operating room & 2 & 11 & \\
\hline other & 1 & 2 & \\
\hline \multicolumn{4}{|l|}{ Catheter insertion operator } \\
\hline PICU staff doctor & 13 & 16 & \\
\hline PICU resident doctor & 31 & 21 & 0,049 \\
\hline Anesthesiologist & 2 & 10 & \\
\hline Other & 5 & 4 & \\
\hline \multicolumn{4}{|l|}{ Catheter insertion site (vein) } \\
\hline internal jugular & 31 & 35 & \\
\hline femoral & 19 & 11 & 0,097 \\
\hline external jugular and subclavian & 1 & 5 & \\
\hline
\end{tabular}

failure ( $\mathrm{p}=0.013)$, tracheal intubation for more than 7 days $(\mathrm{p}=0.001)$, catheter insertion in the PICU $(\mathrm{p}=0.009)$ and insertion performed by the PICU-resident doctor $(\mathrm{p}=0.049)$. Mann-Whitney test revealed an association with length of time the catheter remained in place $(\mathrm{p}=0.018)$.

\section{Risk factors}

Risk factors for CRI defined by univariate logistic re- gression analysis are shown in Table 2. Significant variables on multivariate logistic regression were also significant after adjusting for age categories (Table 3). Furthermore, the analysis of the infection risk related to the reason for admission, by age adjusted multivariate logistic regression, showed that respiratory failure carried a higher risk for $\mathrm{CRI}(\mathrm{p}=0.0051$; $\mathrm{OR}=6.843$; $\mathrm{CI}=1.779-26.314)$.

\section{Pediatric Risk of Mortality}

There was no significant difference between admission PRISM values of cases (average $\pm \mathrm{SD}=9.21 \% \pm 9.26$ ) and controls (average $\pm \mathrm{SD}=11.39 \% \pm 13.85$ ), even after stratification in $<10 \%, 10$ to $30 \%$ and $>30 \%$ ranges. Subsequently, every PRISM value found was tested as a potential cutoff value to predict appearance of infection. Their sensitivities and specificities were plotted to obtain an ROC curve (Figure 1). Considering that an area under the curve $\mathrm{A}_{\mathrm{z}}=0.5$ corresponds to a random performance and that $\mathrm{A}_{\mathrm{z}}=1$ corresponds to a perfect prediction, PRISM score showed a non-discriminating performance for the appearance of catheter-related infections.

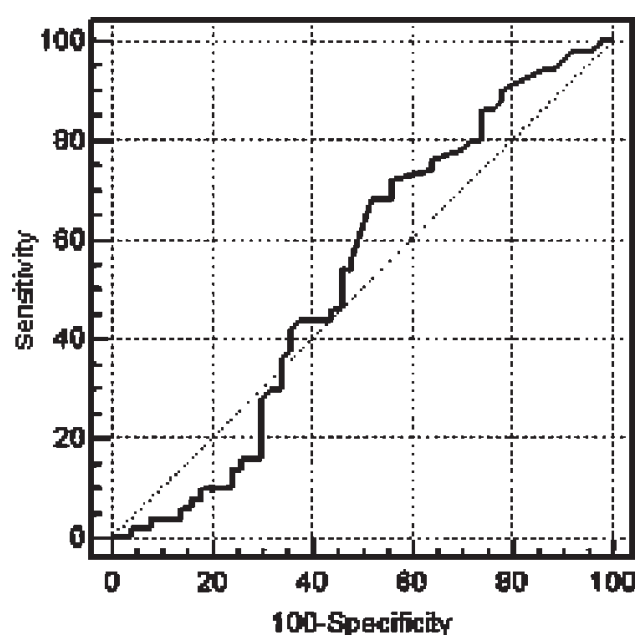

Figure 1 - Admission PRISM score's discriminatory power for catheterrelated infection (CRI) evaluated by Receiver Operating Characteristic (ROC) curve. Area under the curve, $\mathrm{A}_{\mathrm{z}}=0.528(95 \%$ confidence interval $=0.426$ to $0.629)$.

\section{DISCUSSION}

We should emphasize that some measures, such as adherence to aseptic technique during catheter insertion as well as hand hygiene and cleansing of injection ports before catheter manipulation, are necessary for infection control. These and other simple methods must be stressed in continuing education programs because they are essential for reducing infections ${ }^{1}$. 
Table 2 - Analysis of risk factors for catheter-related infection by univariate logistic regression analysis.

\begin{tabular}{|c|c|c|c|}
\hline Variable & $\mathrm{p}$-value & Odds-ratio & CI 95\% \\
\hline \multicolumn{4}{|l|}{ Age } \\
\hline$<1$ year versus $>2$ years & 0.7664 & 1.154 & $0.449 ; 2.961$ \\
\hline 1 to 2 years versus $>2$ years & 0.0214 & 4.121 & $1.233 ; 13.771$ \\
\hline Underlying conditions: chronic lung disease & 0.0704 & 2.831 & $0.917 ; 8.738$ \\
\hline Previous antibiotic therapy ${ }^{\mathrm{a}}$ & 0.1066 & 1.944 & $0.867 ; 4.360$ \\
\hline \multicolumn{4}{|l|}{ Reason for admission } \\
\hline Sepsis ${ }^{\mathrm{b}}$ versus post-operative & 0.6575 & 1.444 & $0.284 ; 7.341$ \\
\hline Respiratory failure versus post-operative & 0.0068 & 5.571 & $1.607 ; 19.314$ \\
\hline Cardiac disease versus post-operative & 0.0713 & 6.500 & $0.850 ; 49.687$ \\
\hline Accident, shock and other versus post-operative & 0.5934 & 1.625 & $0.273 ; 9.658$ \\
\hline \multicolumn{4}{|l|}{ Tracheal intubation } \\
\hline$>7$ days versus $<1$ day or not-intubated & 0.0192 & 5.348 & $1.315 ; 21.749$ \\
\hline 1 day to 7 days versus $<1$ day or not-intubated & 0.9004 & 1.105 & $0.230 ; 5.301$ \\
\hline Insertion scene PICU versus operating room & 0.0152 & 6.945 & $1.452 ; 33.231$ \\
\hline \multicolumn{4}{|l|}{ Operator } \\
\hline PICU resident-doctor versus PICU staff-doctor & 0.2023 & 1.817 & $0.726 ; 4.549$ \\
\hline Anesthesiologist versus PICU staff-doctor & 0.1031 & 0.246 & $0.046 ; 1.328$ \\
\hline Other versus PICU staff-doctor & 0.5747 & 1.538 & $0.342 ; 6.928$ \\
\hline \multicolumn{4}{|l|}{ Insertion site (vein) } \\
\hline Femoral versus internal jugular & 0.1396 & 1.950 & $0.804 ; 4.730$ \\
\hline Number of catheter placements: $>1$ versus 1 & 0.0120 & 3.750 & $1.336 ; 10.523$ \\
\hline Catheter length of stay (median) & 0.0218 & 1.144 & $1.020 ; 1.283$ \\
\hline$>7$ days versus $\leq 7$ days & 0.2336 & 1.612 & $0.735 ; 3.537$ \\
\hline Concomitant antibiotic therapy & 0.0002 & 0.132 & $0.045 ; 0.388$ \\
\hline Blood products administered by $\mathrm{CVC}$ & 0.2336 & 1.612 & $0.735 ; 3.537$ \\
\hline Parenteral nutrition & 0.0230 & 4.020 & $1.211 ; 13.339$ \\
\hline Intermittent infusion + heparin filling versus continuous infusion without heparin & 0.0004 & 0.143 & $0.049 ; 0.420$ \\
\hline
\end{tabular}

a. Up to 30 days before catheter insertion.

b. Includes septic shock.

c. Time from catheter insertion to appearance of infection for cases and from catheter insertion to withdrawal for controls

Table 3 - Analysis of risk factors for catheter-related infections using multivariate logistic regression, adjusted for age.

\begin{tabular}{|c|c|c|c|}
\hline Variable & p-value & Odds-ratio & CI $95 \%$ \\
\hline Number of catheter placements: $>1$ versus 1 & 0.0278 & 5.630 & $1.208 ; 26.251$ \\
\hline Catheter length of stay $>7$ days versus $\leq 7$ days & 0.0155 & 4.121 & $1.310 ; 12.965$ \\
\hline Concomitant antibiotic therapy & 0.0003 & 0.068 & $0.016 ; 0.292$ \\
\hline Intermittent infusion + heparin filling versus continuous infusion without heparin & 0.0008 & 0.082 & $0.019 ; 0.354$ \\
\hline
\end{tabular}

However, in a retrospective study, it may not be possible to examine important variables like catheter insertion conditions, catheter site care and access to ports due to lack of records. Consequently, important risk factors may be hidden. Nevertheless, relevant conclusions can be drawn from the results.

Age

CRBSI rates in pediatric intensive care units are comparatively high, surpassed only by burn and trauma units ${ }^{6}$. Multi-center hospital-acquired infection studies, especially in the PICU, have found either a higher incidence $(p<0.001)$ of primary BSI in children less than 2 months old $^{7}$ or no significant difference in the point-prevalence of nosocomial infections among pediatric age ranges. ${ }^{8}$ In Brazil, one investigation reported a higher frequency of nosocomial infections in children younger than 2 years admitted to a PICU. ${ }^{9}$

In this study, there was no significant difference between the average ages of cases and controls. However, when categorizing age into three ranges, there was a higher incidence of cases in one to two year old children. This result may have been biased by other factors because CRI risk factors that were found by multivariate logistic regression did not include age range and were the same when adjusted for age (Table 3). A biasing factor could be connected to reason for admission because the risk of infec- 
tion related to respiratory failure was significantly higher with age-adjusted logistic regression.

\section{Reason for admission}

Conditions related to respiratory disease, like repeated access to CVC ports for bolus sedation of patients on mechanical ventilation, may have contributed to the association between respiratory failure as a reason for admission and infection. In support of this hypothesis, we observed that patients admitted after eletive operations, who usually require less frequent handling of ports, were significantly more frequent $(\mathrm{p}=0.005)$ among controls than cases.

Patients with CRI had significantly large duration of intubation and longer PICU stays, similar to other authors' results, ${ }^{8,10,11}$ which reflects patient's critical condition, exposure to invasive devices and procedures, repeated access to central lines, selection for resistant bacteria and colonization by nosocomial microorganisms.

\section{Insertion scene, operator and site}

CRIs occurred significantly more often when the catheter was inserted in the PICU (Table 2). However, most of the catheters were inserted in the PICU, and the others were usually inserted in the operating room (OR). PICU-placed CVCs may be associated with a higher incidence of infection due to factors linked to the patients, like their physiopathological condition. In shock and hypoxic-ischemic states, vascular collapse or vasoconstriction complicates percutaneous needle puncture of veins, resulting in hematomas and necrotic tissue, which favor colonization. In addition, critically ill patients need frequent access to CVC ports and invasive procedures. Generally, insertion in the OR occurs in ideal asepctic conditions, anesthesia and hemodynamic control. Furthermore, elective surgical patients have less need for access to CVC ports and shorter durations of device placement than critically ill patients.

Resident doctors generally have less experience in catheter insertion techniques than PICU staff doctors and anesthesiologists. Insertion by a physician with an accumulated experience of 50 or more catheterizations is half as likely to result in a mechanical complication as compared to an insertion by a less skilled doctor. ${ }^{12}$ On preliminary analysis, there was an association between insertion by resident doctor and CRI. Insertion of half of the catheters in the study by resident doctors and more than half of the remaining devices in the OR must have influenced such an association. Furthermore, logistic regression did not identify this variable as a risk factor, suggesting that aseptic techniques and adequate supervision make up for lack of ability. ${ }^{13}$

A randomized study in adults ${ }^{14}$ found that subclavian venous catheterization was associated with a significantly lower rate of total infectious complications than femoral venous catheterization, in which overall mechanical complications are more likely. In a non-randomized study, subclavian vein catheterization resulted in a smaller incidence of CRI than internal jugular vein catheterization. ${ }^{15}$ However, catheterization of the subclavian vein in children is not recommended due to risks of mechanical complications ${ }^{16}$, and there are no consistent reports comparing the risks of infection between the femoral vein and jugular internal vein. In this investigation, there was no association between insertion site and infection, when comparing femoral, internal jugular, external jugular and subclavian veins. Furthermore, logistic regression analysis demonstrated no significant difference in the incidence of infection comparing femoral venous catheterization to internal jugular, although the other sites were used too infrequently to be evaluated.

\section{Catheter use}

Catheter placement for more than 7 days was a risk factor for CRI according to multivariate logistic regression analysis, which agrees with Maki and coworkers' finding that the cumulative risk for CRBSI rises with the length of time the catheter remains in place. ${ }^{17}$ Furthermore, more than one CVC placement resulted in a higher risk of infection in the multivariate analysis. The need for a new CVC could be related to severity of illness, longer PICU stay, number of invasive procedures and frequency of infusions. These are all factors associated with CRBSI. In addition, the presence of multiple intravascular access devices and the total duration of intravascular access device use are associated with an increase in the rate and risk of developing CRBSI. ${ }^{18}$

In this study, the use of antibiotics was a protective factor against CRI. Other authors have reported the efficacy of prophylactic vancomicin in preventing Gram-positive infections in low birth weight neonates, ${ }^{19,20}$ but the emergence of resistant bacteria has discouraged this practice. ${ }^{21}$

In this investigation, blood product transfusion was not associated with CRI, suggesting that colonization was not significant even though transfusion could have favored thrombosis. Additionally sepsis caused by blood products contaminated with bacteria has been reported as a rare incident. $^{22}$

While parenteral nutrition was associated with CRI, it was not statistically identified as a risk factor in the multivariate logistic regression. probably because of the short administration period; the relationship between 
parenteral nutrition and infection is stronger when parenteral nutrition lasts for more than 7 days. ${ }^{23}$ Moreover, the practice of designating one port to exclusively administer parenteral nutrition was observed when a multilumen catheter was in place. ${ }^{1}$

In a meta-analysis, the use of either intra-luminal conventional or subcutaneous low weight heparin reduced the risk of thrombosis, but neither substantially changed the CRBSI rate. ${ }^{24}$ Because the majority of heparin solutions contain preservatives with antimicrobial activity, it is unclear whether the observed decrease in the rate of CRBSI was a result of reduced thrombus formation or an effect of preservatives. In this survey, catheters receiving continuous infusion flow had a higher risk of CRI when compared to catheters that remained in intermittent use, alternating with heparin flush, in the multivariate logistic regression analysis. One could conclude that heparin had a protective action against infection, but it is necessary to emphasize that continuous infusion was administered to severely ill patients who needed intravenous maintenance fluids, parenteral nutrition and continuous infusion drugs like inotropes, vasopressors, vasodilators and sedatives, as well as intermittent medications. On the other hand, CVCs with intermittent infusions followed by heparin flush were used in less critical situations, when patients received enteral nutrition and probably fewer medications, with less chance for contamination.

\section{Pediatric Risk of Mortality}

Although the PRISM score was designed to predict the mortality of populations, it has also been used to predict morbidity, including nosocomial infections. ${ }^{3,4}$ However, the results of this study do not support the use of PRISM to evaluate the risk for CVC-related infections. PRISM is composed strictly of physiological and laboratory variables $^{25}$, variables directy related to the appearance of infections (c.g. the use of invasive devices). The inclusion and the other risk factors identified in this study would allow for the development of more adequate scores for nasocomial infections. ${ }^{26}$

\section{CONCLUSIONS}

In conclusion, enteral nutrition should substitute parenteral nutrition, and catheters should be withdrawn as soon as possible because it is relatively easy to reduce these risk factors. The relative safety of femoral vein catheterization suggested by these results, in which its risk for infection is comparable to jugular vein catheterization, should be investigated in a controlled trial. Adequate supervision and respect to aseptic techniques may compensate for resident doctors' lack of skill in catheter insertion. The Pediatric Risk of Mortality score should not be used to predict the risk for central catheter-related infections. A more specific score that includes variables clearly related to the development of nosocomial bloodstream infection, like the use of invasive devices, should be available to predict the risk of central venous catheter-related infections in children.

\section{ACKNOWLEDGEMENTS}

We thank Dr. Sônia R. P. E. Dantas, for clarifying concepts of hospital infection surveillance, Dr. Plínio Trabasso, president of the hospital infection control committee, for the open doors and files, and Dr. Carlos Eduardo Lopes for his contributions regarding pediatric intensive care medicine.

\section{RESUMO}

Vilela R, Jácomo ADN, Tresoldi AT. Fatores de risco para as infecções relacionadas ao cateter venoso central em terapia intensiva pediátrica. Clinics. 2007;62(5):537-44.

OBJETIVOS: Identificar fatores de risco para as infecções relacionadas a cateter venoso central de curta permanência, inserido por punção, em crianças e avaliar a eficiência de um escore de mortalidade pediátrica em prever o risco de infecção.
MÉTODOS: Revisão dos casos de infecção relacionada a cateter ocorridos na unidade de terapia intensiva pediátrica de um hospital universitário seguida de estudo caso-controle com 51 pares. Foram analisadas variáveis relacionadas aos pacientes e à inserção e utilização dos cateteres, sendo definidos fatores de risco por análise de regressão logística. A eficiência de Pediatric Risk of Mortality em discriminar o risco de infecção foi testada pela curva receiver operating characteristic. 
RESULTADOS: Foram variáveis associadas à infecção: insuficiência respiratória, duração da internação, tempo de intubação, inserção do cateter na unidade de terapia intensiva e nutrição parentérica. $\mathrm{O}$ sítio de inserção foi indiferente quando comparadas as veias jugular interna e femoral. Foram fatores de risco: inserção de mais de um cateter $(p=0,014)$ e tempo de permanência do cateter $(p=0,0013)$. Foram fatores de proteção: uso concomitante de antibióti$\cos (p=0,0005)$ e infusão intermitente seguida de heparinização quando comparada à infusão contínua sem heparinização $(\mathrm{p}=0,0002)$. Pediatric Risk of Mortality não discriminou o risco de infecção.

CONCLUSÕES: Deve-se suspender a nutrição parentérica e retirar o cateter venoso central assim que possível. A cateterização da veia femoral implica em risco de infecção semelhante ao da veia jugular interna. O escore Pediatric Risk of Mortality não deve ser utilizado para estimar o risco de infecção relacionada ao cateter venoso central.

UNITERMOS: Infecção Hospitalar. Fatores de Risco. Cateterismo Venoso Central. Criança. Cuidados Intensivos.

\section{REFERENCES}

1. Centers for Disease Control and Prevention. Guidelines for the prevention of intravascular catheter-related infection. MMWR 2002;51(RR-10):1-29

2. De Jonge RCJ, Polderman KH, Gemke RJBJ. Central venous catheter use in the pediatric patient: mechanical and infectious complications. Pediatr Crit Care Med 2005;6:329-339

3. Pollock E, Ford-Jones EL, Corey M, Barker MD, Mindorff CM, Gold R et al. Use of the Pediatric Risk of Mortality score to predict nosocomial infection in a pediatric intensive care unit. Crit Care Med 1991;19:160165

4. Arantes A, Carvalho ES, Medeiros EAS, Farhat CK, Mantese OC. Pediatric risk of mortality and hospital infection. Infect Control Hosp Epidemiol 2004;25:783-785

5. Pearson ML, Hospital Infection Control Practices Advisory Committee (HICPAC). Guideline for prevention of intravascular-device-related infections. Infect Control Hosp Epidemiol 1996;17:438-473

6. National Nosocomial Infections Surveillance System. National Nosocomial Infections Surveillance (NNIS) System report, data summary from January 1992 to June 2002, issued August 2002. Am J Infect Control 2002;30:458-475

7. Richards MJ, Edwards JR, Culver DH, Gaynes RP, National Nosocomial Infection Surveillance System. Nosocomial infections in pediatric intensive care units in the United States. Pediatrics 1999;103:804-810

8. Grohskopf LA, Sinkowitz-Cochran RL, Garrett DO, Sohn AH, Levine GL, Siegel JD et al. A national point-prevalence survey of pediatric intensive care unit-acquired infections in the United States. J Pediatr 2002;140:432-438

9. Abramczyk, ML, Carvalho, WB, Carvalho, ES, Medeiros, EAS Nosocomial infection in a pediatric intensive care unit in a developing country. Braz J Infect Dis 2003;7:375-380

10. Slonim AD, Kurtines HC, Sprague BM, Singh-Naz N. The cost associated with nosocomial bloodstream infections in the pediatric intensive care unit. Pediatr Crit Care Med 2001;2:170-174
11. Yogaraj JS, Elward AM, Fraser VJ. Rate, risk factors, and outcomes of nosocomial primary bloodstream infection in pediatric intensive care unit patients. Pediatrics 2002;110: 481-485

12. Sznajder JI, Zveibil FR, Bitterman H, Weiner P, Bursztein S. Central vein catheterization: failure and complication rates by three percutaneous approaches. Arch Intern Med 1986;146:259-61

13. Coopersmith CM, Rebmann TL, Zack JE, Ward MR, Corcoran RM, Schallom ME et al. Effect of an educational program on decreasing catheter-related bloodstream infections in surgical intensive care unit. Crit Care Med 2002;30:59-64

14. Merrer J, De Jonghe B, Golliot F, Lefrant JY, Raffy B, Barre E et al. Complications of femoral and subclavian venous catheterization in critically ill patients: a randomized controlled trial. JAMA 2001;286:700-707

15. Heard SO, Wagle M, Vijayakumar E, Mclean S, Brueggemann A, Napolitano LM et al. Influence of triple-lumen central venous catheters coated with chlorhexidine and silver sulfadiazine on the incidence of catheter-related bacteremia. Arch Intern Med 1998;158:81-87

16. American Heart Association. Vascular access. In: Hazinski MF ed. PALS provider manual. EUA, 2002.

17. Maki DG: Infections caused by intravascular devices used for infusion therapy: pathogenesis, prevention, and management. In: Bistro AI, Waldvogel FA eds. Infections associated with indwelling medical devices, Second Edition. Washington: ASM Press, 1994

18. Odetola FO, Moler FW, Dechert RE, VanDerElzen K, Chenoweth C. Nosocomial catheter-related bloodstream infections in a pediatric intensive care unit: risk and rates associated with various intravascular technologies. Pediatr Crit Care Med 2003;4:432-436

19. Kacica MA, Horgan MJ, Ochoa L, Sandler R, Lepow ML, Venezia RA. Prevention of Gram-positive sepsis in neonatos wighting less than 1500g. J Pediatr 1994;125:253-258

20. Spafford PS, Sinkin RA, Cox C, Reubens L, Powell KR. Prevention of central venous catheter-related coagulase-negative staphylococcal sepsis in neonates. J Pediatr 1994;125:259-263 
21. Centers for Disease Control and Prevention (CDC). Recommendations for preventing the spread of vancomicyn resistance. Recommendation of the Hospital Infection Control Practices Advisory Committee (HICPAC). MMWR 1995; RR12, 44pp

22. Wagner SJ, Friedman LI, Dodd RY. Transfusion-associated bacterial sepsis. Clin Microbiol Rev 1994;7:290-302

23. Yeung CY, Lee HC, Huang FY, Wang CS. Sepsis during total parenteral nutrition: exploration of risk factors an determination of effectiveness of peripherally inserted central venous catheters. Pediatr Infect Dis J 1998;17:135-142
24. Randolph AG, Cook DJ, Gonzáles CA, Andrew M. Benefit of heparin in central venous and pulmonary artery catheters: a meta-analysis of randomized controlled trials. Chest 1998;113:165-171

25. Pollack MM, Ruttimann UE, Getson PR. Pediatric risk of mortality (PRISM) score. Crit Care Med 1988;16:1110-1116

26. Singh-Naz N, Sprague BM, Patel KM, Pollack MM. Risk assessment and standardized nosocomial infection rate in critically ill children. Crit Care Med 2000;28:2069-2075 